\title{
Effects of polyculture and monoculture farming in oil palm smallholdings on tropical fruit-feeding butterfly diversity
}

\begin{abstract}
1. In many developing countries, commercial oil palm farming supports the livelihood of millions of small-scale farmers in the rural areas. However, forest conversion into oil palm monocultures has a major impact on tropical biodiversity. In existing oil palm production landscapes, little is known about how different oil palm agricultural practices affect farmland biodiversity, particularly insect biota.

2. We quantified fruit-feeding butterfly species richness and community composition in oil palm areas subject to polyculture and monoculture farming in Peninsular Malaysia. Polyculture smallholdings were predicted to support greater butterfly diversity than monoculture smallholdings because of the greater structural complexity and floristic diversity associated with crop diversity in polyculture smallholdings.

3. We also identified local-scale habitat attributes important for maintaining fruit-feeding butterfly species richness.

4. We found no significant differences in butterfly species richness, abundance and the composition of butterfly assemblages between polyculture and monoculture smallholdings. Local-scale habitat quality explained $32.1 \%$ of the variation in fruit-feeding butterfly richness in oil palm smallholdings.

5. We found that polyculture farming failed to increase fruit-feeding butterfly diversity as a result of a limited number of crop species in oil palm smallholdings. To improve current agricultural practices and maintain high levels of butterfly diversity, commercial growers should increase the number of crop species planted in oil palm smallholdings.
\end{abstract}

Keyword: Agricultural practice; Biodiversity; Butterfly; Habitat quality; Oil palm; Smallholdings 